See Article page 149.

\section{Commentary: Can ultrasound contribute to our understanding of postoperative delirium?}

\author{
Hilary P. Grocott, MD, FRCPC, FASE
}

In this issue of the Journal, Beaubien-Souligny and colleagues $^{1}$ expand on their previously described theory ${ }^{2}$ that postoperative delirium may be the result of a syndrome that they describe as a "congestive encephalopathy." That is, these events may be related to cerebral venous congestion that results from right ventricular (RV) dysfunction and its consequence of elevated right-sided venous pressures. This venous congestion can then lead to interstitial edema and increased intracranial pressure, both of which can potentially lead to impaired cerebral function and even a reduction in cerebral blood flow and all its adverse sequelae (eg, cerebral ischemia). This follows similar work by this group examining the impact of elevated venous pressures on other organ dysfunction, including acute kidney injury. ${ }^{3}$ Along with this, they have extensively studied the means to diagnose the root cause of these various congestive organopathies by using Doppler ultrasonography of the portal vein. Indeed, the presence of portal vein pulsatility appears to be an easy to interrogate and reliable indicator of $\mathrm{RV}$ dysfunction. ${ }^{4}$

In attempting to uncover a unifying cause for these various forms of organ dysfunction, they have put forth an interesting potential theory. However, additional studies will be needed to more confidently determine the mechanistic role that these factors may play. Indeed, it is just as easy to consider that this venous congestion may just be epiphenomenal and not at all directly related. That is, those who are "sicker" after surgery or have major significant comorbidities (and who would not agree that significant $\mathrm{RV}$ dysfunction is in that category) may simply have

\footnotetext{
From the Department of Anesthesiology, Perioperative and Pain Medicine, University of Manitoba, Winnipeg, Manitoba, Canada.

Disclosures: Author has nothing to disclose with regard to commercial support.

Received for publication Feb 19, 2020; accepted for publication Feb 20, 2020; available ahead of print March 10, 2020.

Address for reprints: Hilary P. Grocott, MD, FRCPC, FASE, University of Manitoba, St Boniface Hospital, CR3008-369 Tache Ave, Winnipeg, Manitoba, Canada R2H 2A6 (E-mail: hgrocott@sbgh.mb.ca).

J Thorac Cardiovasc Surg 2021;161:154-5

$0022-5223 / \$ 36.00$

Copyright (c) 2020 by The American Association for Thoracic Surgery

https://doi.org/10.1016/j.jtcvs.2020.02.092
}

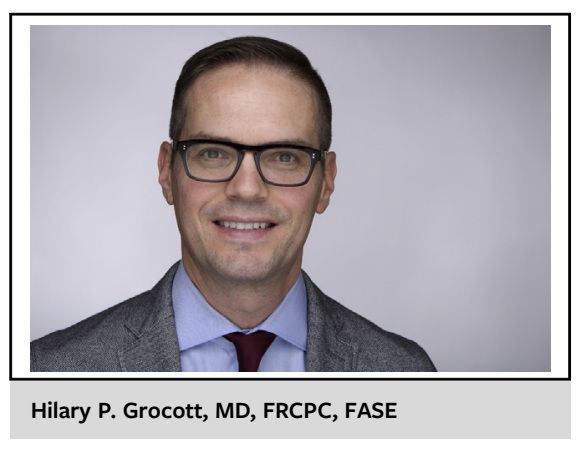

CENTRAL MESSAGE

Additional studies are needed to

more confidently understand

any link between ultrasound-

derived indices of RV dysfunction

and potential encephalopathy

from cerebral venous

congestion.

more delirium due to their overall medical conditions and not those directly related to RV dysfunction per se. The complexities of the brain (and other organs) make it challenging to believe that there is one unifying cause (ie, congestive encephalopathy) for the cerebral dysfunction (delirium) that is seen in this setting. This line of investigation certainly warrants pursuing, but this point should be interpreted with balanced caution. These experts have extensive experience with the use of ultrasound to investigate RV dysfunction and its vascular sequelae (ie, portal vein pulsatility ${ }^{5}$ ), so it is logical for them to look for links between the findings of these readily available tools and other diagnoses. However, just as a "hammer considers everything a nail," it is logical for ultrasound experts to focus on ultrasound-related etiologies for all the patient's ills. The evidence is at best indirect and should not detract from other efforts to determine the causes of, and potential solutions for, this seemingly ever-present problem in patients after cardiac surgery.

\section{References}

1. Beaubien-Souligny W, Cavayas YA, Denault A, Lamarche Y. First step toward uncovering perioperative congestive encephalopathy. J Thorac Cardiovasc Surg. 2021;161:149-53.e1.

2. Benkreira A, Beaubien-Souligny W, Mailhot T, Bouabdallaoui N, Robillard P, Desjardins G, et al. Portal hypertension is associated with congestive encephalopathy and delirium after cardiac surgery. Can J Cardiol. 2019;35:1134-41.

3. Beaubien-Souligny W, Benkreira A, Robillard P, Bouabdallaoui N, Chassé M, Desjardins G, et al. Alterations in portal vein flow and intrarenal venous flow 
are associated with acute kidney injury after cardiac surgery: a prospective observational cohort study. J Am Heart Assoc. 2018;7:e009961.

4. Eljaiek R, Cavayas YA, Rodrigue E, Desjardins G, Lamarche Y, Toupin F, et al. High postoperative portal venous flow pulsatility indicates right ventricular dysfunction and predicts complications in cardiac surgery patients. Br J Anaesth 2019;122:206-14.

5. Denault AY, Azzam MA, Beaubien-Souligny W. Imaging portal venous flow to aid assessment of right ventricular dysfunction. Can J Anaesth. 2018;65:1260-1. 